\title{
An Overview on Pharmaceutical Supply Chain: A Next Step towards Good Manufacturing Practice
}

\author{
Kapoor $\mathbf{D}^{\mathbf{1}}$, Vyas $\mathbf{R B}^{\mathbf{1}}$ and Dadarwal $\mathrm{D}^{\mathbf{2}}$ \\ ${ }^{1}$ Dr. Dayaram Patel Pharmacy College, India \\ ${ }^{2}$ Sanjeevni College of Pharmaceutical Sciences, India
}

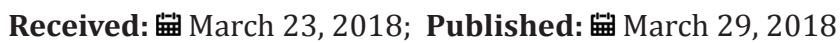

*Corresponding author: Devesh Kapoor, Dr. Dayaram Patel Pharmacy College, Sardar baug, Station Road, Bardoli, Surat, Gujarat, India

\begin{abstract}
The top priority in any health system is delivering of medicine as a strategic product. In the present context of a health-conscious society, management of pharmaceutical supply chains has become more complex because it involves the life-saving interest of human being and requires the participation of different stakeholders such as pharmaceutical manufacturers, wholesalers, distributors, customers, information service providers and regulatory agencies. Limited research is available in the area of pharmaceutical supply chains. Pharmaceutical companies, a most important player of the drug supply chain, are subject to many risks. These risks interrupt the quantity and quality of supply of medicine and their delivery to the accurate place and customers and at the correct time.
\end{abstract}

Keywords: Drug Counterfeiting; Temperature Controlled Logistics; Supplier Qualification; Performance Management; Globalization; Sustainability

Abbreviations: OTC: Over the Counter; CDSCO: Central Drug Standards and Control Organization; NPPA: National Pharmaceutical Pricing Authority; RFID:Radio Frequency Identification Technology; EPC: Electronic Product Code; EPC: Electronic Product Code

\section{Introduction}

Supply chain management is defined as the amalgamation of key business processes across the supply chain for the rationale of generating value for customers and stakeholders. Indeed supply chain management integrates supply and demand within and across companies in an efficient business model. [1,2] The Council of Supply Chain Management Professionals defines supply chain management as planning and management of all activities involved in sourcing, procurement, conversion and all logistics activities. There are a variety of aspects of evaluating in the supply chain; eliminating bottlenecks, balancing between tiniest material cost and transportation, optimizing manufacturing flow, maintaining the right mix and location of factories and warehouses, vehicle routing analysis, dynamic programming and efficient use of capacities, inventories, and labors are of main aspects of supply chain optimization $[3,4]$. All stockholders need to institute the right configuration and adaptability to create best practice and to overcome the obstacles in continues changing environment. Pharmaceutical supply chain should provide medicines in the right quantity, with the acceptable quality, to the right place and customers, at the right time and with optimum cost to be consistent with health system's objectives and also it should make benefits for its stockholders. Supply chain is a set of players, processes, information, and resources which transfers raw materials, and components to finished products or services and delivers them to the customers. It includes suppliers, intermediaries, third-party service providers and customers. It also includes all of the logistics activities, manufacturing operations and activities with and across marketing, sales, product design, finance and information technology [5-7].

\section{Benefits of Supply Chain Management}

Supply chain management in the pharmaceutical industry can renovate the organization to make better use of assets and resources, to engender profits, to boost shareholder value, and to optimistically respond to customer demand. Effective supply chain management can effect and develop virtually all business processes, 
such as data accuracy, operational complexity reduction, supplier selection, purchasing, warehousing and distribution. Other benefits include [8]:
a) Quicker customer response and fulfilment rates
b) Shorter lead time
c) Greater productivity and lower costs
d) Reduced inventory supply throughout the chain
e) Improved forecasting precision
f) Fewer suppliers and shorter planning cycles

\section{The Pharmaceutical Supply Chain}

After a drug is launched, a completely different set of objectives, drivers, and constraints become dominant. The key stakeholders in this supply chain include multiple government agencies, hospitals, clinics, drug manufacturers, drug distributors, pharmacy chains, retailers, research organizations, and the FDA. To compound matters further, the same supply chain is responsible for the distribution of prescription drugs, over-the-counter (OTC) medicines, generics, as well as biologics having different handling needs and operational objectives. Indeed, there are numerous other organizations, such as insurance companies, healthcare management organizations, and GPOs, that further increase the complexity. Due to very different business objectives, these organizations make the task of managing supply chain all the more difficult. Furthermore, due to the regulatory nature of the industry and numerous merger and acquisitions to acquire more $R \& D$ expertise, many pharmaceutical supply networks have grown in an uncontrolled fashion rather than being planned for optimal performance [9] (Figure 1).

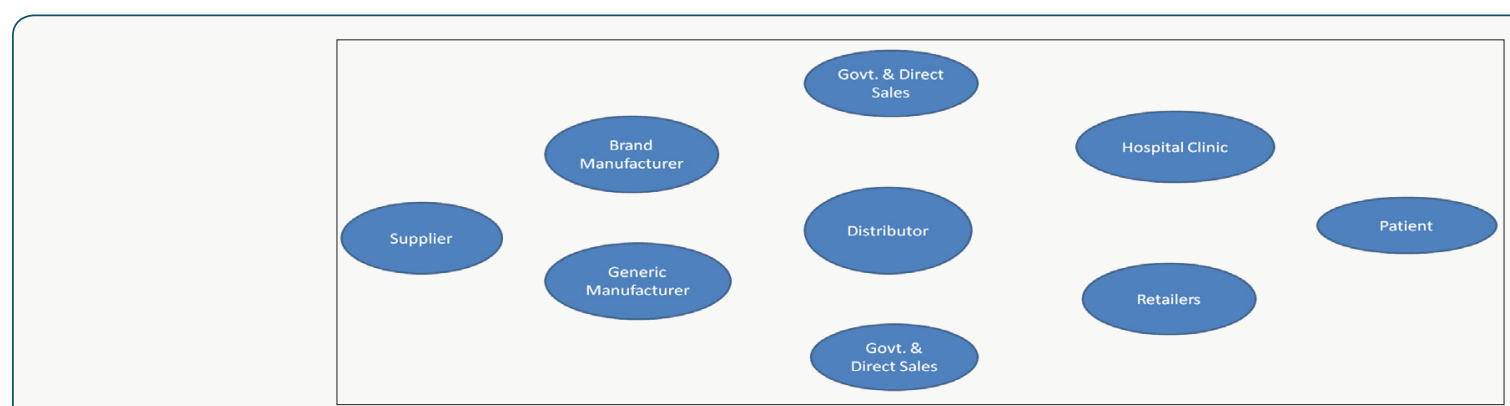

Figure 1: The Pharmaceutical Supply Chain.

\section{Main Issues Related to Pharmaceutical Supply Chain}

i. Issues related to Counterfeiting.

ii. Unfavorable reaction of the drug to the patients.

iii. Issues rose due to entities of supply chain operations.

iv. Manufacturing issues like mixing incorrect input raw materials, or cross contamination due to manufacturing more than one drug in the same facility, or improper labeling of the final product.

v. Retailer's issues including improper temperature controls and handling.

vi. Transportation issues caused by mishandling, improper temperature controls, and the use of improper shipping mode.

vii. Storing and warehousing issues such as using improper temperature controls, improper handling in the warehouse and mixing products with raw materials.

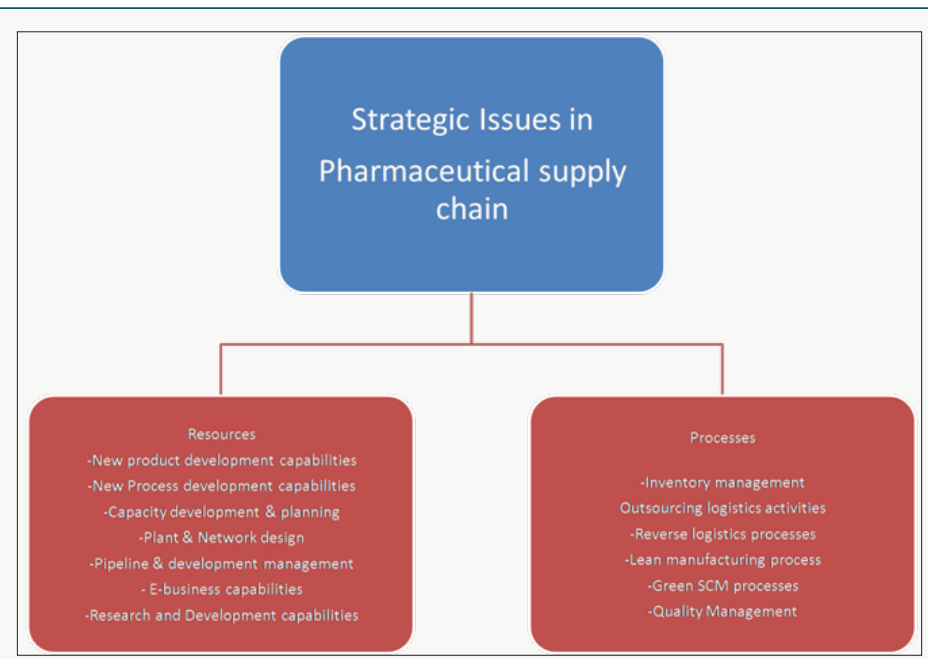

Figure 2: Strategic issues in pharmaceutical supply chain. 
viii. Raw material suppliers issues like improperly prepared raw material, raw material with high impurity levels and mislabeling of raw material shipments (Figure 2).

\section{The Regulatory System}

The regulatory system of the Government of India has a federal form that divides the medical regulatory system into national and state authorities. The principal regulatory bodies that are answerable for the approval, production, and marketing of quality drugs in India are the following entities [10]: a. Central Drug Standards and Control Organization (CDSCO): This agency sets standards to ensure the safety and quality of drugs, diagnostics, cosmetics, devices, and supervision of the importation of drugs.

b. National Pharmaceutical Pricing Authority (NPPA): This agency fixes or revises the prices of decontrolled bulk drugs.

c. Ministry of Chemicals and Petrochemicals: This organization supervises pharmaceutical sector policy, planning, development, and regulatory activities pertaining to the chemicals, petrochemicals (Figure 3).

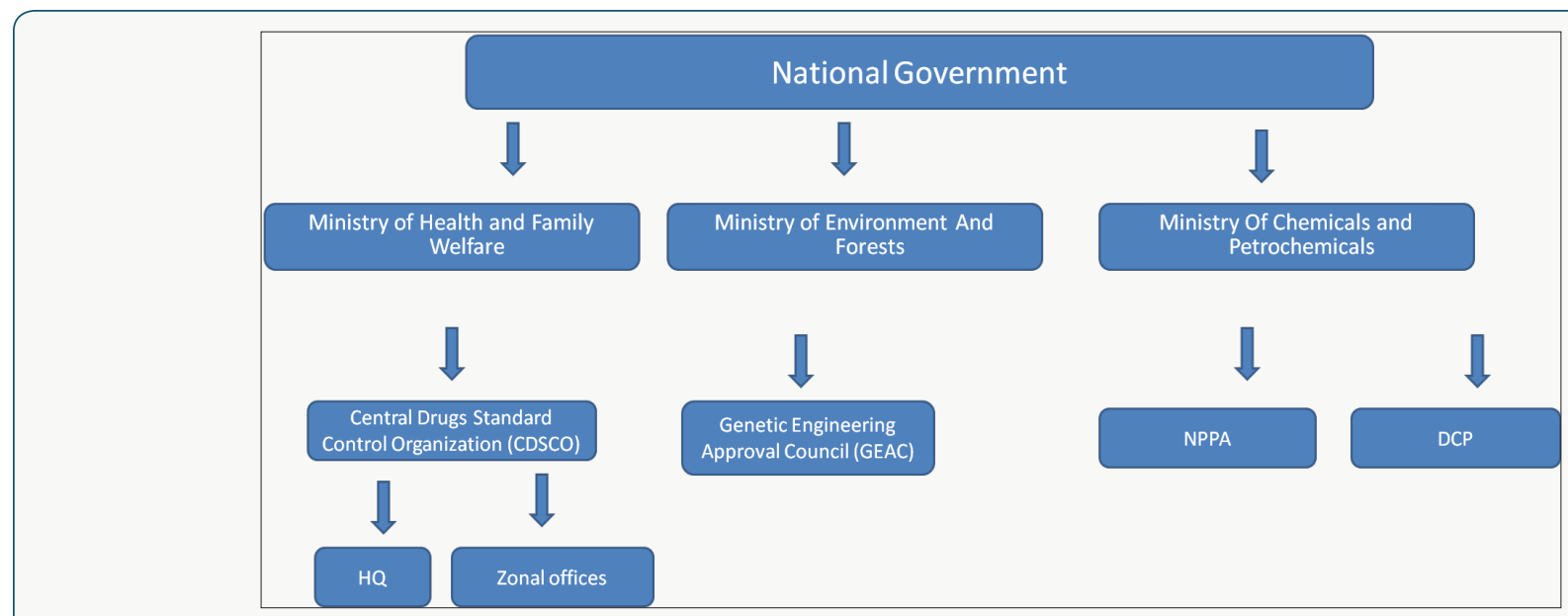

Figure 3: Regulatory system of government of India.

\section{Temperature Controlled Logistics}

India is a vast continent with different temperatures and environmental conditions varying 25 to $500 \mathrm{c}$ at different places. This presents a whole different set of challenges for the drug manufacturers to ensure drugs are maintained at the requisite temperatures throughout theirlifecycle. The problem of temperature controlled logistics is one of the common noteworthy problems. The failure to maintain drugs at their prescribed temperature often results in the loss of efficacy. The drugs that require stringent cold storage and transport are often expensive and are often targeted by the drug counterfeiters due to their high value.

\section{Radio Frequency Identification Technology (RFID) and Electronic Product Code (EPC) and its Effect on The Pharmaceutical Supply Chain $[11,12]$}

A RFID system fundamentally consists of four items, a host computer, readers, encoders and tags. Tags are manufactured of a microchip, size is approx $0.2 \mathrm{~mm}$ or $0.4 \mathrm{~mm}$ and a bendable antenna entrenched in a plastic-coated inlay having numerous forms and dimensions depending on the context and performance required. The information can be written onto the tags by an encoder printer, which is consequently read by a reader that converts the electromagnetic wave pattern coming from the tag into digital signals and transmits them to the information system by a terminal computer. Data are stored into the tag chip in the form of an Electronic Product Code (EPC).

\section{Benefits of RFID in Healthcare}

a) RFID technology allows the automatic retrieval of relevant patients' histories eliminating errors due to manual data entry.

b) Real-time monitoring of both location and status of the patients can drastically improve their safety.

c) By eliminating manual data entry requirements and enabling authorised staff to rightly access a patient's status anywhere, both an increase in efficiency and a decrease in overall costs can be obtained.

d) RFID-equipment tracking enables assets to be found instantly and their service ensured in a timely manner, thus increasing the patients' safety.

e) In order to secure the Healthcare \& Life Sciences against counterfeits, an electronic pedigree based on RFID/EPC technology may make criminal drug diversion more difficult. This is a secure document that details data about each move a product makes along the supply chain, from the manufacturer through wholesalers to pharmacies and healthcare providers.

\section{Challenges in Pharmaceutical Supply Chain}

i. Lack of coordination

ii. Inventory management 

iii. Absent demand information
iv. Human resource dependency
v. Order management
vi. Shortage avoidance
vii. Expiration
viii. Warehouse management
ix. Temperature control
X. Shipment visibility

\section{Lack of Adherence to Prescription}

Medical practitioners and heath care experts who participated in the study acknowledged the problem of lack of adherence to a prescription. According to the experts, lack of adherence to prescription can manifest itself in the following forms:

a. Terminations of drug consumption after major symptoms subside.

b. Self medication with drugs left over the previous instance of illness.

These practices represent multiple ill effects for patients and drug manufacturers:

i. Self medication and its associated problems.

ii. Spreading of contagious disease due to incomplete cure.

iii. Revenue leakages.

iv. Inaccurate data for macro analysis of disease spread and drug efficacy (Figure 4).

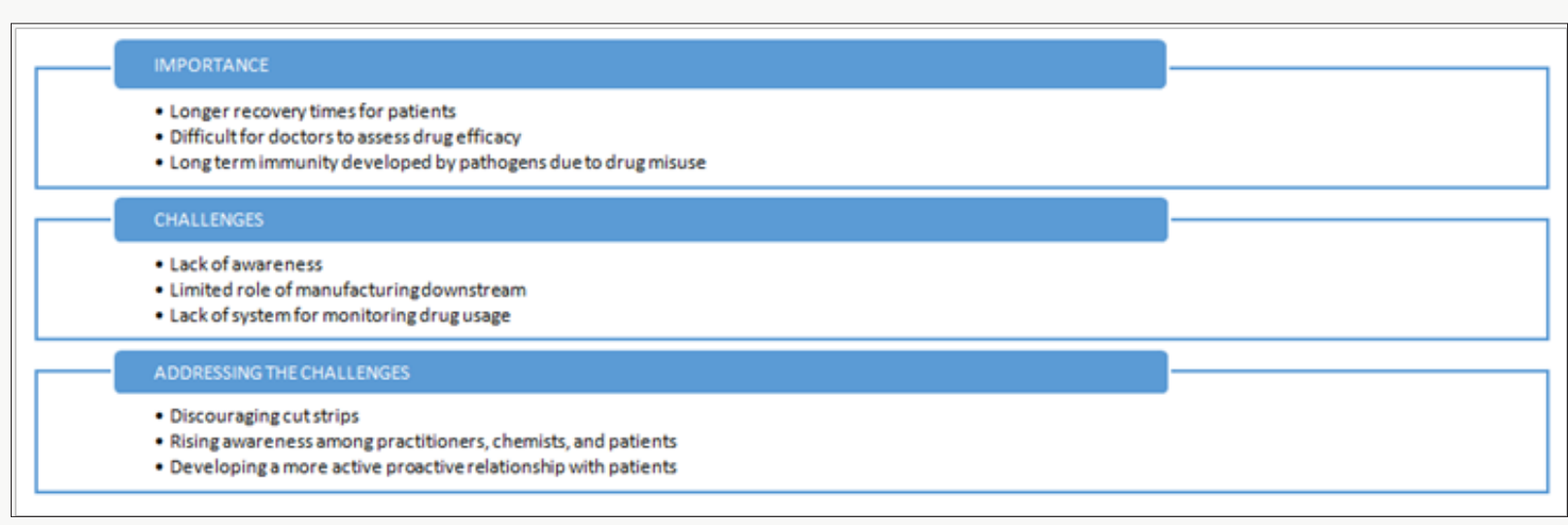

Figure 4: Summary of lack of adherence to prescription.

\section{Drug Counterfeiting}

Counterfeiting of goods is widespread across many sectors like FMCG, electronics and apparel. But nowhere is its impact as profound and devastating as the counterfeiting of pharmaceuticals. There is a severe economic and social practice to be paid by patients. Counterfeiters are criminal opportunists. They target markets in countries where the capacity to detect defective products and the penalty for engaging in counterfeiting are low. Compounding the magnitude of the problem is the complex nature of the current pharmaceutical supply chains where drug development, API manufacturing, formulation, packaging and final consumption may often circle the globe multiple times. The low investment high return aspect, difficulty in detection of counterfeits, multiple potential points of leakage into the legitimate drug supply chain and limited visibility of movement of inventory and stocks offer an added incentive to criminal elements to pursue this activity.

This counterfeiting challenge should be addressed by a multi prolonged strategy centred on the following 3 grounds (Figure 5):

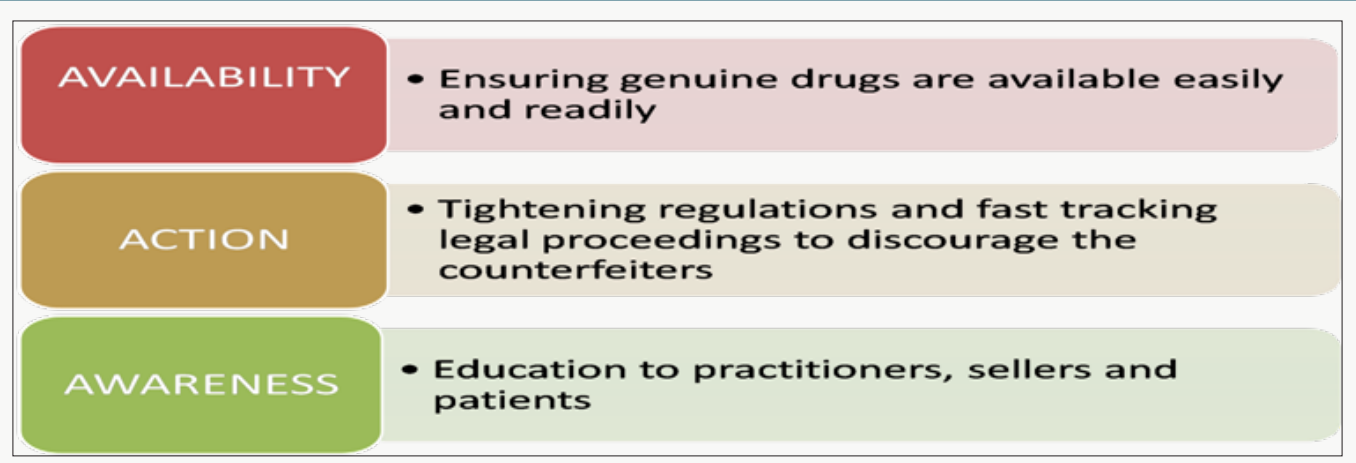

Figure 5: Three pronged approach. 

a) Availability
b) Action
c) Awareness

The goal is to create a drug supply chain that is flexible enough to respond quickly to the actions of counterfeiters while simultaneously being lean enough to minimize the effort of policing along with reducing the potential points leakage to a minimum. Technology is currently being deployed to tackle the following key aspects of the process:

a) Track and trace

b) Detection
c) Packaging
d) Online trade

\section{Supplier Qualification}

A supplier is a person or organization which provides something which is needed like a product or service. Since there are many products and services supplied to a pharmaceutical industry, the scope of this process is wide spread (Figure 6). The suppliers to be qualified and very different from each other and hence the procedure needs to be framed depending on the criticality of the material and its impact on the product. A high level of understanding of the nature of the product supplied will aid in this process (Figure 7).

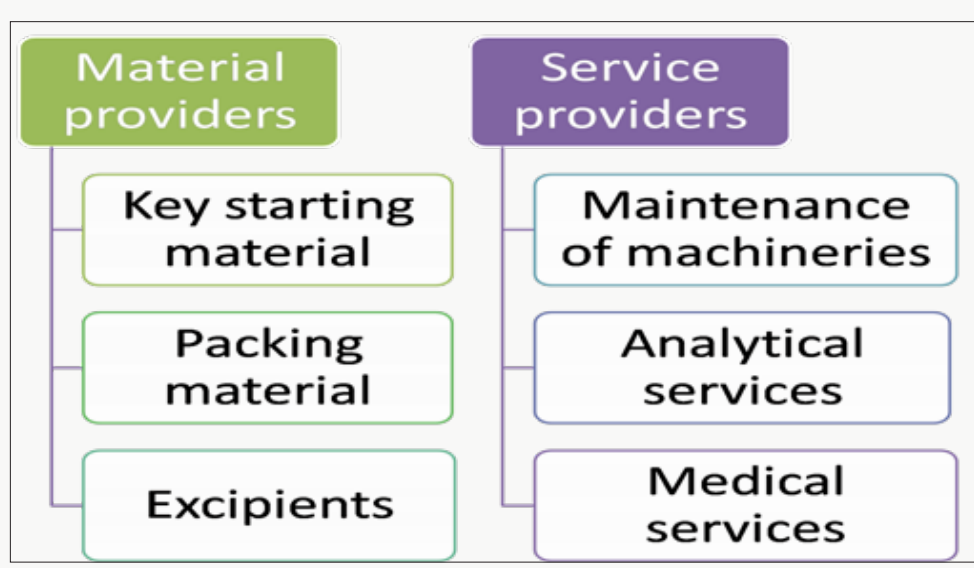

Figure 6: Material and services providers.

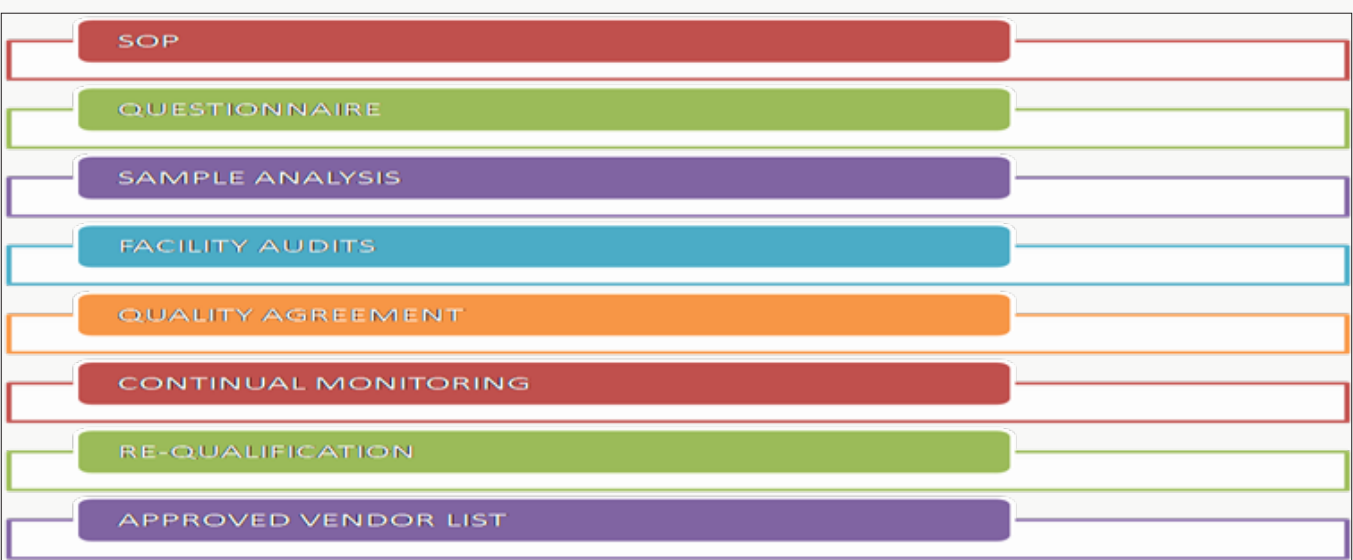

Figure 7: Basic elements of supplier qualification.

\section{Standard Operating Procedure for Supplier Qualification (SOP)}

The scope of SOP is spread to new material being purchased from a new vendor, existing material from a new vendor, and new material from an existing vendor. This scope also involves service providers of various services. The responsibility of this process lies with the purchase department to find vendors for the required products and services. The quality control personnel is responsible to test and approve the samples of materials of the supplier under review. The brief procedure of this qualification programme is outlined below (Figure 8).

\section{Conclusion}

In supply chain, performance of pharmaceutical companies as a main player has noteworthy impact on supply chain management efficiency. Identify the risk and prevent them in pharmaceutical companies not only can lead to process optimization, productivity augment and plummeting business risk, but also will help health 
systems to meet goals of supply chain management; Accessibility, Quality and Affordability. Supplier qualification through a complex process is very crucial to design right quality for the product and services. Every step in this process is critical and needs to be followed. A good information practice that is sharing of information between the supplier and the end user can lead to satisfactory supplier qualification.

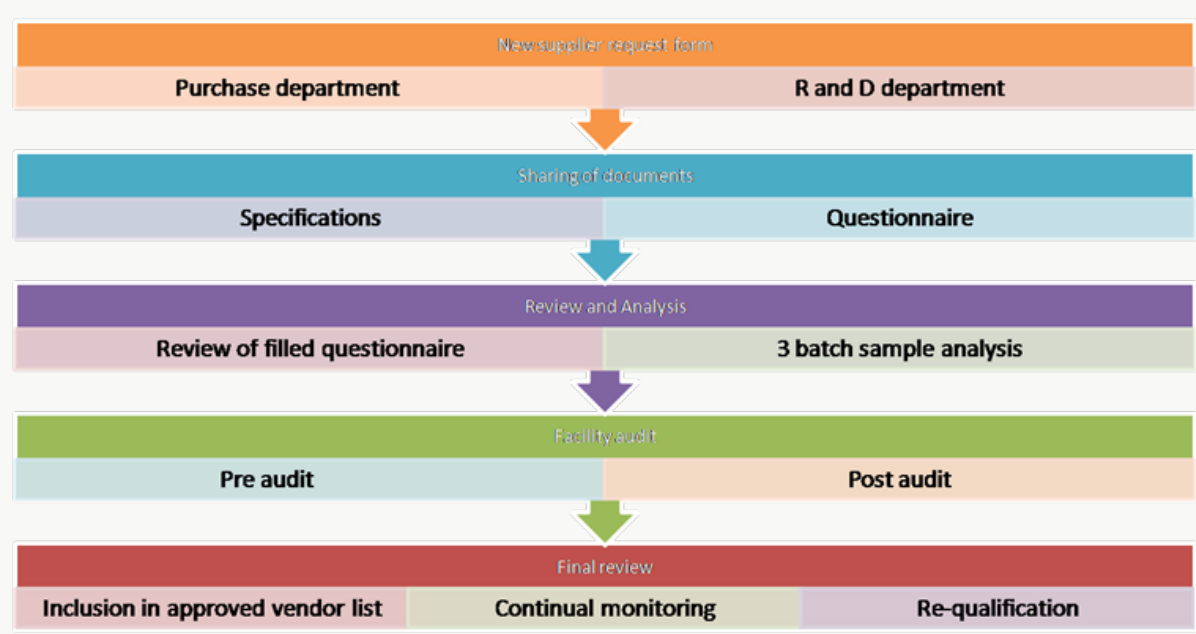

Figure 8: Standard operating procedure for supplier qualification.

\section{References}

1. Rossetti CL, Handfield R, Dooley KJ (2011) Forces, trends, and decisions in pharmaceutical supply chain management. Int J Phys Distr Log 41: 601-622.

2. Shah $N$ (2004) Pharmaceutical supply chains: key issues and strategies for optimisation. Computers \& Chem Eng 28(6-7): 929-941.

3. Dinarvand R, Jahanbakhsh H (2001) Evaluation and modeling of regional drug distribution in Iran. Teb Va Tazkieh 42: 1.

4. Wisner JD, Tan KC, Leong GK (2011) Principles of supply chain management: a balanced approach. Thomson South Western, USA.

5. Sousa RT, Liu SS, Papageorgiou LG, Shah N (2011) Global supply chain planning for pharmaceuticals. Chem Eng Res Des 89(11): 2396-2409.

6. Naraharisetti PK, Karimi IA (2010) Supply chain redesign and new process introduction in multipurpose plants. Chem Eng Sci 65(8): 25962607.
7. Juttner U, Christopher M, Baker S (2007) Demand chain managementintegrating marketing and supply chain management. Ind Market Manag 36(3): 377-392.

8. Deisingh AK (2005) Pharmaceutical counterfeiting. Analyst 130(3): 271-279.

9. McFarlane D, Sheffi Y (2003) The impact of automatic identification on supply chain operations. The International Journal of Logistics Management 3: 1-17.

10. Saranga H, Phani BV (2009) Determinants of operational efficiencies in the Indian pharmaceutical industry. International Transactions in Operational Research 16(1): 109-130.

11. Koroneos G (2005) Purdue's RFID Pedigree Program Enters Pilot Phase. Pharmaceutical Technology.

12. McCormick D (2006) Cardinal Health Reports on RFID Pilot. ePT-the Electronic Newsletter of Pharmaceutical Technology.

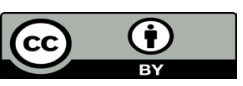

This work is licensed under Creative Commons Attribution 4.0 License

Submission Link:

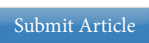

DOI: 10.32474 /DDIPIJ.2018.01.000107

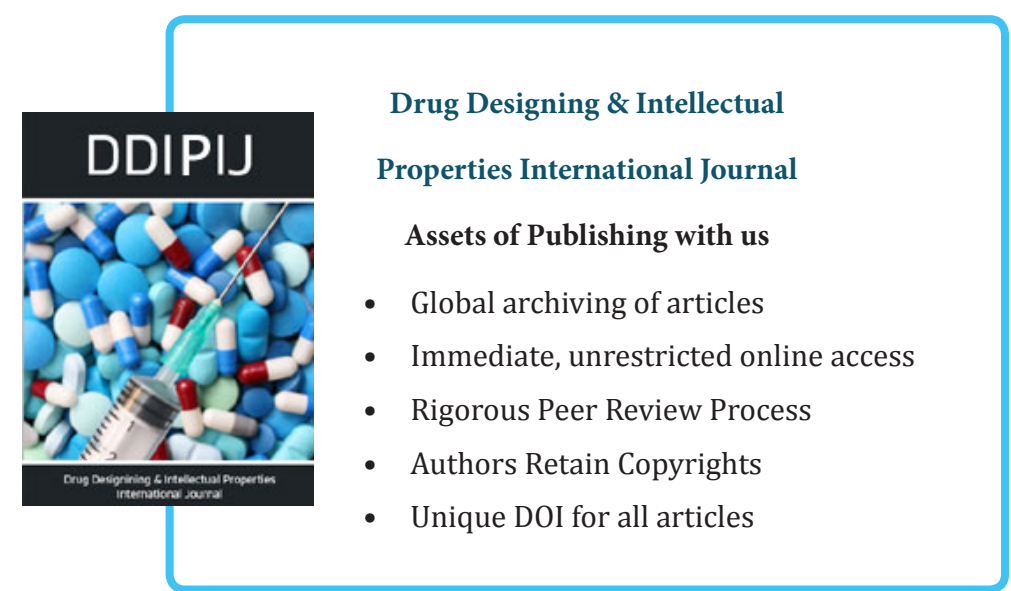

